\title{
Investigating patterns of carbon convergence in an uneven economy: The case of Turkey
}

\author{
Sevil Acar ${ }^{\mathrm{a}, \mathrm{b}, *}$, A. Erinç Yeldan ${ }^{\mathrm{c}}$ \\ a Department of Economics, Altınbaș University, Istanbul, Turkey \\ ${ }^{\mathrm{b}}$ Boğaziçi University - Center for Climate Change and Policy Studies, Turkey \\ c Department of Economics, Ihsan Dogramaci Bilkent University, Ankara, Turkey
}

\section{A R T I C L E I N F O}

\section{Article history:}

Received 11 August 2017

Received in revised form 9 February 2018

Accepted 29 April 2018

Available online 7 May 2018

\section{Keywords:}

Carbon convergence

Climate policy

Emission intensity

Sectoral emissions

Turkey

\begin{abstract}
A B S T R A C T
Turkey is known to suffer from severe volatility in its growth patterns, as well as from the uneven sectoral growth and employment. Volatile rates of emissions across sectors are further manifestations of this uneven structure. The purpose of this study is two-fold: first, we check for dynamic patterns of convergence of carbon dioxide $\left(\mathrm{CO}_{2}\right)$ emissions across sectors; and second, using evidence from panel data econometrics, we search for the determinants of these processes utilizing macroeconomic explanatory variables. We find that, based on various alternate criteria, $\mathrm{CO}_{2}$ emissions display conditional convergence mainly driven by the business cycle. Furthermore, across sectors, high technology activities display convergence over time; and yet, medium technology sectors that constitute the bulk of the aggregate value added display either poorly convergent or divergent trends. These results reveal that much of the emissions convergence is driven by the business cycle rather than the workings of discretionary mitigation policy.
\end{abstract}

(C) 2018 Elsevier B.V. All rights reserved.

\section{Introduction}

Environmental convergence research has been inspired by the conventional economic convergence literature, and has used similar methodologies to inspect cross-country dynamics of emissions convergence for various samples and different time spans. The idea stems from the fact that the evolution of income and pollution cannot be separated from each other. Income generation generally requires energy use and energy is usually generated via the extraction of natural resources and the use of fossil fuels that emit pollutants and gases including carbon. Needless to say, these are all dependent on the economic activities of households, firms and governments; and the choices of these actors under certain policy and technology constraints play a role in changing the amount of emissions that are released to the atmosphere.

In a contemporary setting, $\mathrm{CO}_{2}$ convergence is especially important in this respect due to the ongoing discussions of international agreements on emissions cuts and the implementation of policy tools such as carbon taxes or carbon trading schemes. As widely

\footnotetext{
* Corresponding author at: Department of Economics, Altınbaş University, Istanbul, Turkey.

E-mail addresses: sevil.acar@altinbas.edu.tr, sevil.acar@boun.edu.tr (S. Acar), yeldane@bilkent.edu.tr (A.E. Yeldan).
}

known, the Paris Agreement aims to limit global warming to below $2{ }^{\circ} \mathrm{C}$, and further motivate the international efforts to limit it to $1.5^{\circ} \mathrm{C}$. Consequently it bears collective responsibility for all countries. The most prominent feature of the post-Paris Agreement era is that all parties to the Agreement pledge some emission reduction targets and adopt measures to curb emissions in accordance with the principle of "common but differentiated responsibilities and respective capabilities" as stated on the United Nations Framework Convention on Climate Change. Within this framework, all countries need to contribute to the global efforts to fight climate change by various measures and policies in order to transform their economic sectors into low-carbon forms. Hence, both developed and developing countries have emission reduction responsibilities that entail declining sectoral emissions at differentiated rates.

Put differently, a low-carbon economic development path across the globe requires that greenhouse gas (GHG) emissions need to converge to lower levels globally, regionally, and sectorially. If there is weak evidence of carbon convergence in per capita emissions at the global level, "global agreements that impose convergence may generate large re-distributional impacts, significant transfers of wealth, and thus a burden of large adjustment costs" (Acar et al., 2018: 7). Therefore, policy makers need to overreach single allocation rules and extend the policy sphere across raising knowledge about the impacts of combined scenarios, and developing new approaches to climate change adaptation and mitigation. 
What is more, "even in the possible presence of carbon dioxide convergence, global climate policy must also consider whether countries then tend to converge to higher or lower per capita levels" (Acar et al., 2018: 7). Given the broad consensus that the main instrument of climate change mitigation should fundamentally be accompanied with increased efficiency of energy utilization as well as technological and institutional change that allow for decoupling of economic activity from environmental pollution, the question of sectoral patterns of carbon emissions become of due importance.

Turkey is grappling with the challenges of ensuring a costcompetitive energy supply for its growing population and the industrial sectors, ensuring energy security, and reducing its GHG emissions. A key hypothesis of this study is that the projected lack of decoupling between growth and GHG emissions is mostly driven by the uneven patterns of growth and industrialization across Turkey. Yeldan et al. (2013) suggest that one of the main causes of the productivity slowdown of the Turkish economy over the 2010s is the diverging patterns of regional development and the widening gap across high versus low income regions, as well as modern versus traditional sectoral production (and consumption) patterns. Besides, high-pollution industries have been relocating from the more developed cities of the country to the less-developed central and eastern regions.

On the other hand, across sectors Turkey is suffering from patterns of heterogeneity that are characteristic of many lateindustrializing nations. Transfer of the rural labor surplus to modern sectors occurs at an uneven pace, labor markets remain fragmented and heterogenous simply because capital in most cases remains heterogenous. Under conditions of differentiated rates of growth sectorially, emissions tend to follow divergent patterns, straining policy effectiveness. We believe that such relocation of industries that bear different environmental pressures could also play a role in interregional and intersectoral economic convergence and/or divergence.

The analysis of the current study departs from individual sectors in Turkey. To this end, we check for evidence on convergence of $\mathrm{CO}_{2}$ emissions across sectors utilizing various methods including panel data econometrics over sectoral data. These examples are, of course, not generalizations, but show how certain sectoral experiences would fit the big picture of global carbon convergence (or divergence). In continuation of evidence on convergence, if any, we search for the leading indicators of these processes by way of differentiating the production sectors according to their level of technology and energy utilization. We distinguish between primary (low) technology, medium technology, and high technology sectors. Besides, the main results are given an interpretation from the perspective of the sectors which experienced the highest transformation pressures owing to high oil prices over the investigated period (especially in the 2000s), e.g. coke, refined petroleum and nuclear fuel; chemicals and chemical products; and rubber and plastics. Hence, this study contributes to the literature in two main aspects. First, to the best of our knowledge, this is the first study to undertake an analysis of sectoral carbon convergence in Turkey. Second, it emphasizes the need to distinguish between different economic sectors with respect to their technological sophistication. Consequently, such categorization helps to track differing convergence and/or divergence patterns in $\mathrm{CO}_{2}$ emissions due to the fact that sectors might have varying levels of technological openness or ease of access to energy saving technologies that may help them adopt external economies of scale and reduce pollution intensities.

The paper is organized as follows: In the following section, we summarize the GHG statistics of Turkey through the lens of climate change by casting comparative figures from the rest of the world. We provide a brief survey on the theoretical background and pertinent literature in section three. Next, we introduce our methodology and data sources in section four. We study alter-

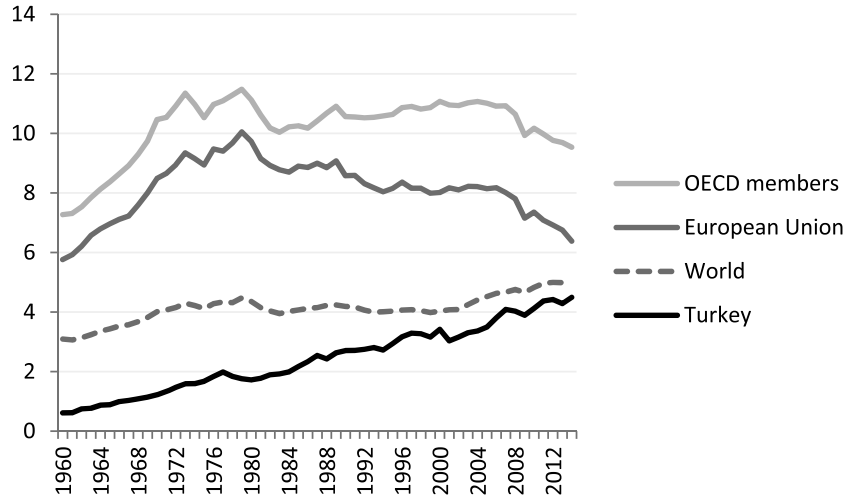

Fig. 1. $\mathrm{CO}_{2}$ emissions (metric tons per capita). Source: World Development Indicators (2018).

native configurations of sectoral convergence in section five. We summarize the results and conclude in section six.

\section{A glance at Turkey's gaseous emissions through the lens of climate change and economic growth}

Turkey's economy is known to display wide swings in its patterns of growth both in aggregate and also in its sectoral composition. The stop-and-go patterns of output growth are manifested not only in terms of mini-business cycles of economic activity, but also in terms of gaseous emissions across sectors. As of 2015, Turkey's total emissions of gaseous pollutants (in terms of carbon dioxide equivalent $\left(\mathrm{CO}_{2}\right.$ eq. $)$ is estimated to be 475 million tons (mtons). About three quarters of this is reported to arise from energy-related activities, while 61 mtons are attributed to industrial processes. According to data from the Turkish Statistical Institute (2015), with total emissions of 6 tons of $\mathrm{CO}_{2}$ eq. per capita in 2015, Turkey displays a lower figure in emissions in both total and per capita accounts than many countries. The World Bank's World Development Indicators (2018) reveal that $\mathrm{CO}_{2}$ emissions reached 9.5, 6.4, 5 metric tons per capita for the OECD, European Union (EU) and the world respectively in 2014, whereas Turkey's per capita $\mathrm{CO}_{2}$ emissions were at 4.5 metric tons per capita in the same year (see Fig. 1).

However, Turkey is also known to display one of the highest rates of growth in $\mathrm{CO}_{2}$ eq. emissions among the emerging market economies. Turkey's aggregate $\mathrm{CO}_{2}$ eq. emissions increased from 214 million tons in 1990, to 475 million tons in 2015, corresponding to a cumulative increase of $122 \%$ during the period. Several studies project that the country's GHG emissions will keep accelerating in the near future, climbing, for instance, up to 675 million tons by 2030 (Acar and Yeldan, 2016). This suggests that Turkey will be on a divergent trend against many of the emerging market developing economies as well as the world averages over the next decades.

These assessments are succinctly narrated in Fig. 2a and b below, where we display the rate of change in aggregate $\mathrm{CO}_{2}$ eq. emissions against changes in real GDP over the post-1990 era. The close association between the real rate of change in $\mathrm{CO}_{2}$ emissions and the real business cycles over this period is clearly visible for Turkey, suggesting that the much desired decoupling of gaseous emissions from real economic activity has not yet taken place. This observation further reveals the low elasticity of gaseous emissions in response to real growth, and that the returns to abatement policies had rather been dismal. This fact contrasts with the Asian emerging economies, where a substantial decoupling of gaseous emissions from real GDP growth is observable (see Fig. 2a and b).

Besides, although $\mathrm{CO}_{2}$ emissions from electricity and heat production (as a percentage of total fuel combustion) make the bulk of 
(a)

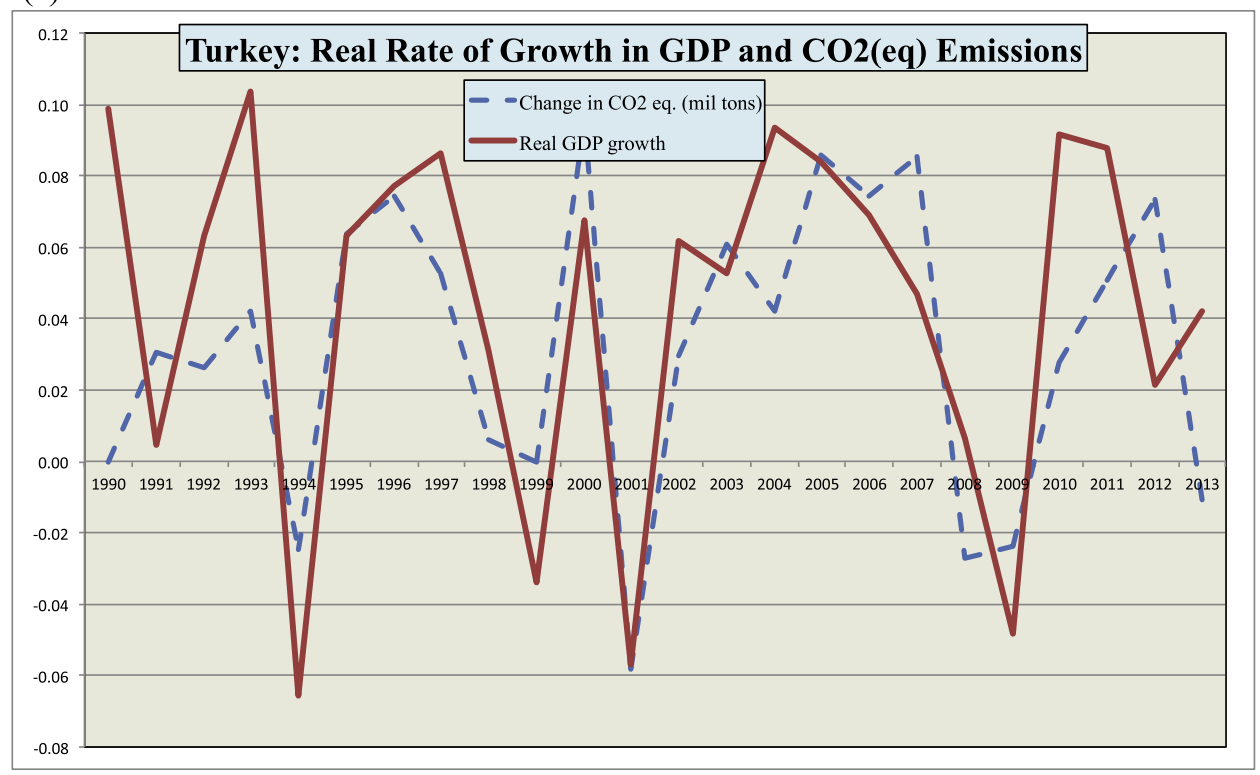

(b)

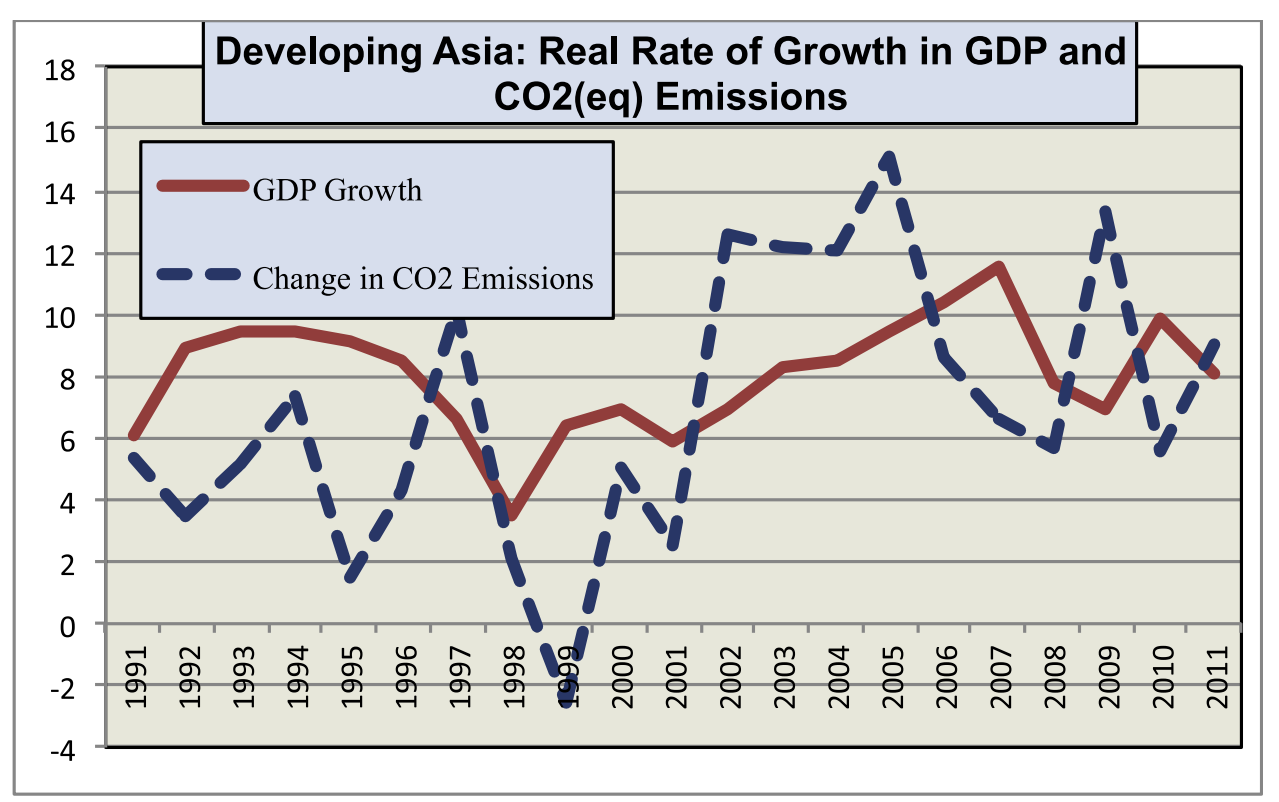

Fig. 2. a and b. $\mathrm{CO}_{2}$ and GDP growth rates in Turkey versus Asian countries.

the emissions in Turkey as well as in the OECD, EU and the world, the distribution of emissions across other sectors shows variability. For instance, the share of emissions from residential buildings and commercial and public services is found to be much higher in Turkey than the OECD, EU and the world averages in 2012. Similarly, the share of $\mathrm{CO}_{2}$ emissions from manufacturing industries and construction is well above the OECD and EU averages whereas it remains below the world average in 2012. More strikingly, while Turkey's emissions from manufacturing declined sharply following the global economic turmoil, those emissions did not experience secular declines in the OECD or the EU on average. Emissions from transport as a share of total fuel combustion, on the other hand, are lower than the corresponding averages (see Fig. 3). The declining trend of transport-related emissions in Turkey from 1960 to 2012 contrasts with inclining trends of such emissions in the OECD and EU (World Development Indicators, 2016).

A key hypothesis in this paper is that the projected lack of decoupling between growth and emissions mitigation is mostly driven by the uneven patterns of growth and industrialization across sectors in Turkey. Yeldan et al. (2013) suggest that one of the main causes of the productivity slowdown of the Turkish economy over the 2010s is due to the diverging patterns of regional and sectoral development and the widening gap across high versus low income regions, as well as modern versus traditional sectoral production (and consumption) patterns. We argue that the lack of mitigation at the aggregate national level finds its manifestation in this widening gap across regional and sectoral stratification of income, production capacities, as well as the consequent carbon and gaseous emissions. 


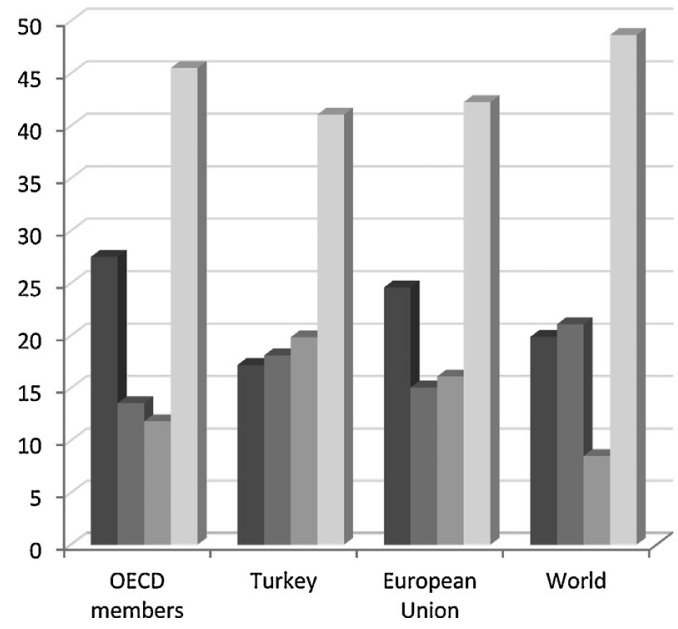

- $\mathrm{CO} 2$ emissions from transport (\% of total fuel combustion)

- $\mathrm{CO} 2$ emissions from manufacturing industries and construction (\% of total fuel combustion)

- $\mathrm{CO} 2$ emissions from residential buildings and commercial and public services (\% of total fuel combustion)

CO2 emissions from electricity and heat production, total (\% of total fuel combustion)

Fig. 3. Sectoral $\mathrm{CO}_{2}$ emissions in the world, $\mathrm{EU}, \mathrm{OECD}$, and Turkey in 2012 (\% of total fuel combustion). Source: World Development Indicators (2016).

\section{Background theory and literature}

It is widely known that convergence in per capita income is rooted in the Solow model (Solow, 1956), which stipulates that countries (or regions) at lower per capita income levels tend to experience higher growth rates than the richer ones. This idea is due to the traditional (mainstream) assumption of diminishing marginal returns to capital. The implications of this hypothesis have been tested frequently in the empirics of growth literature.

Convergence in terms of environmental quality, as a recent concept, has been studied in several recent articles and reports. As pointed out by Brännlund et al. (2015), an important aspect of this literature has been to analyze the conditions under which an economy can achieve economic growth combined with nondeteriorating environmental quality. One general condition, which emanates from the optimality conditions in a dynamic neoclassical growth model, is pollution $(\beta)$ convergence, implying that, in the long-run, pollution should be bounded as well as approach a steady-state level even in the presence of positive growth in per capita GDP.

Inspired by previous economic convergence research, environmental convergence literature devotes itself to investigate whether convergence across environmental indicators or the amount of pollutants (particularly, emissions) exists across various regions and time periods (e.g. List, 1999; Strazicich and List, 2003; Lee and List, 2004; Nguyen-Van, 2005; Aldy, 2006, 2007; Bulte et al., 2007; Ezcurra, 2007; Westerlund and Basher, 2008; Camarero et al., 2008; Panopoulou and Pantelidis, 2009; Brock and Taylor, 2010; and Camarero et al., 2013). The bulk of this research has focused on carbon convergence; by utilizing either cross-country data or panel data comprising of countries (see Pettersson et al. (2014) for a comprehensive review). At the expense of over-generalization, the main finding of this research is that convergence in per capita carbon dioxide emissions is realized to some extent between the developed (OECD) countries, while evidencing relatively persistent gaps or divergence at the global level. In addition, studies on regional convergence have also investigated patterns of pollutants across regions. For instance, List (1999) tests for convergence of $\mathrm{SO}_{2}$ and $\mathrm{NO}_{\mathrm{x}}$ for 10 US regions during the period 1929-1994 and finds limited evidence of convergence. Similarly, Lee and List (2004) conduct unit root tests for $\mathrm{NO}_{\mathrm{x}}$ in US states from 1900 to 1994 demonstrating that $\mathrm{NO}_{\mathrm{x}}$ emissions are not converging since the series are non-stationary and contain a unit root. Aldy (2007) and
Bulte et al. (2007) are also among those who concentrate on US regional emissions.

Research on sectoral convergence, however, remains relatively limited. Some studies focus on "environmental performance" in search for environmental convergence. For instance, Brännlund et al. (2015) investigate the convergence of $\mathrm{CO}_{2}$ performance across the 14 Swedish manufacturing sectors from 1990 to 2008 . They first calculate an environmental performance index derived from production of both the good and bad outputs. Then they estimate the growth of this index (i.e. the rate of change in the ratio of the inverse emission intensity) based on the initial value of the index and other factors such as sectoral capital intensity, fossil fuel use, fossil fuel price, value added and EU ETS participation. They detect conditional $\beta$-convergence in $\mathrm{CO}_{2}$ performance together with the contribution of higher fossil fuel prices to improved $\mathrm{CO}_{2}$ performance in the Swedish industrial sectors whereas they find no significant effect of EU ETS participation. Similarly, Morleo and Gilli (2016) analyze the environmental performances of 14 manufacturing sectors in the EU (excluding Crotia), using the ratio between value added and carbon dioxide emissions (i.e. environmental productivity) as the performance indicator for the period 1995-2009. Using data from the World Input-Output Database (WIOD), the authors find that there is evidence for $\beta$-convergence conditional on the role of variables like trade openness and policy for sectorial environmental performance. This implies that sectors with lower initial levels of environmental productivity demonstrate higher growth rates of environmental productivity than those that have already experienced good environmental performances. Besides, they find that trade openness fosters environmental productivity, whereas technology, proxied by the compound growth rate of the knowledge stock (measured through patent applications), appears to be insignificant. On the other hand, they do not detect any evidence of $\sigma$-convergence for the same sample.

Recently, more studies have started to concentrate on sectoral GHG emissions in search for convergence. Wang and Zhang (2014) study per capita $\mathrm{CO}_{2}$ emissions in 28 provinces and six sectors in China. They evidence convergence in all the sectors from 1996 to 2010, and report different factors that lead to convergence. For instance, GDP per capita and population density are the determinants of convergence in the industry sector as well as in the transportation, storage, postal, and telecommunications services sector. Apart from GDP per capita and population density, trade openness also influences convergence in the wholesale, retail, 
trade, and catering services. Finally, convergence of emissions due to residential consumption is mainly shaped by population density.

Another study that quests for sectoral emissions convergence is Moutinho et al. (2014), which analyzes $\mathrm{CO}_{2}$ intensity of the Portuguese industry. The authors find sigma convergence for all sectors as well as provide evidence for the significant roles of fossil fuel use and energy consumption in determining sectoral $\mathrm{CO}_{2}$ emissions and emissions intensity. With a focus on a single sector, Moutinho (2015) divides the tourism sector into various subsectors with respect to their energy use and investigates the carbon convergence (and divergence) patterns in these sectors. He detects sigma convergence generally in accommodation and food services, transport and wholesale and retail trade sub-sectors when the dispersion of their emission intensities between 1996 and 2003 is considered; however he finds divergence in the corresponding sectors between 2003 and 2006.

In their search of whether the measures taken within the EU to meet its commitments for climate change mitigation have had the desirable impacts, Morales-Lage et al. (2017) question if convergence occurred over the period 1960-2012 in sectoral per capita $\mathrm{CO}_{2}$ emissions in the EU. By utilizing time series techniques to $\mathrm{CO}_{2}$ data for the 28 member countries, the authors test for stochastic and club convergence. As a result, they detect meager evidence of club convergence due to the fact that while several EU countries keep increasing their emissions, the others do better at limiting emissions considerably. Yet, the authors observe major differences among the sectors and sub-sectors considered. For instance, the transport sector (as a sub-sector of energy) is found two display two convergence clubs with nine and seven member countries respectively, whereas there are eight non-converging countries in terms of emissions from transport. Similarly, two convergence clubs of six member countries each are detected for the manufacturing sector (again, as a sub-sector of energy), while two diverging clubs with two and nine countries respectively are identified. Finally, divergence for fifteen countries is detected in emissions from power generation and heating, which, in general, is a significant source of emissions throughout the EU.

Apergis and Payne (2017) conduct a similar analysis for fifty US states (including the District of Columbia) utilizing the PhillipsSul club convergence approach for the period 1980-2013. Their findings evidence that there are multiple convergence clubs "in the aggregate, by sector (residential, commercial, industrial, transport, and electric power), and for two of the three fossil fuel sources (natural gas and coal) with full panel club convergence in the case of petroleum" (Apergis and Payne, 2017: 365). The authors interpret these results as a way to recognize the need to design differential environmental policies that would identify the differences in the convergence paths of various sectors.

Oliveira and Bourscheidt (2017) investigate per capita GHG emissions convergence for a multi-sectorial panel of countries. They make use of random and fixed effects panel data models as well as Arellano and Bond's (1991) GMM estimator. They find strong and robust evidence of "per capita convergence in $\mathrm{CH}_{4}$ emissions in the agriculture, food, and services sectors", whereas "the evidence of convergence in $\mathrm{CO}_{2}$ emissions was moderate in the following sectors: agriculture, food, non-durable goods manufacturing, and services" (Oliveira and Bourscheidt, 2017: 402).

To the best of our knowledge, the current study is the first of its type in the analysis of sectoral carbon convergence in Turkey. Despite not searching for convergence, Kumbaroğlu (2011) conducts a sector decomposition analysis of Turkey's $\mathrm{CO}_{2}$ emissions during the period 1990-2007, and highlights the scale effect as the major source of emission growth in the electricity, manufacturing, and transport sectors. He attributes emission growth in the household and agriculture sectors to energy intensity. Comparing the leading growth engines of the Turkish economy for the periods
1995-2002 and 2003-2009, Aşıcı (2015) also illustrates that the latter period is characterized by growth in more energy intensive sectors and "the composition of the economic activity is concentrated in more $\mathrm{CO}_{2}$ and $\mathrm{NO}_{\mathrm{x}}$ intensive sectors" (Aşıcl, 2015: 1738).

\section{Methodology, data and sources}

The notion of convergence can be investigated through three concepts: sigma $(\sigma)$ convergence, stochastic convergence, and beta $(\beta)$ convergence.

To begin with, sigma $(\sigma)$ convergence takes into account the dynamics and the intra-distributional behavior of a selected emission series. Barro and Sala-i-Martin (1992) describe $\sigma$-convergence as the decrease in the cross-section variance of emissions over time. Up to this aim, cross-sectional variance or standard deviation is simply plotted to detect convergence. Other studies have examined the behavior of relative emissions $\left(R E_{i t}\right)$, where relative emissions are measured as the log of one country's or sector's emissions $(y)$ at time $t$ divided by the yearly sample average $\bar{y}_{t}$, as notated by Carlino and Mills (1993) as follows:

$R E_{i t}=\ln \left(y_{i t} / \bar{y}_{t}\right)$

Second, stochastic convergence focuses on the time series characteristics of the emission series. Using time series analysis, stochastic convergence can be explored to detect whether shocks to emissions for country or sector $i$ relative to another country or sector $j$ (or the average of the sample) are temporary (see Pettersson et al. (2014) for further details). If the time series of interest does not contain a unit root and is proven to be trend stationary, the series is found to be stochastically converging. Many studies including Strazicich and List (2003); Lanne and Linski (2004); McKitrick and Strazicich (2005); Romero-Ávila (2008); Westerlund and Basher (2008); Lee and Chang (2009); Nourry (2009), and Yavuz and Yilanci (2013) make use of various unit root tests to trace stochastic convergence of emissions in different samples of countries. This method can also be implemented for panel data by using panel unit root techniques, which will be employed in the next section of the current study.

Third, beta $(\beta)$ convergence occurs "when the emissions of a poorer country, with lower initials levels of emissions per capita, tend to grow faster than the ones from a rich country and there is a catching-up effect with the more polluting countries" (Pettersson et al., 2014: 149). $\beta$-convergence can be investigated both in a cross-section and panel data setting. The cross-sectional approach implies that convergence is examined by regressing the logged period growth rate of emissions $\ln \left(y_{i t} / y_{i 0}\right)$ (for the whole sample) on the initial logged emission levels, $\ln y_{i 0}$, and an error term $\varepsilon_{i}$ for country, region, or sector $i$ as in below (Pettersson et al., 2014: 150):

$\ln \left(y_{i t} / y_{i 0}\right)=\alpha+\beta \ln \left(y_{i 0}\right)+\varepsilon_{i}$

where $\varepsilon_{i}$ is the error term for country or region $i$. Accordingly, $\beta<0$ implies convergence. Similarly, panel $\beta$-convergence can be analyzed as in the following equation (Pettersson et al., 2014: 151):

$\ln \left(y_{i t} / y_{i, t-\tau}\right)=\alpha^{\prime}+\beta^{\prime} \ln \left(y_{i, t-\tau}\right)+\delta_{i}+\eta_{t}+\varepsilon_{i t}$

where $\ln \left(y_{i t} / y_{i, t-\tau}\right)$ is the growth rate of emissions between $t-\tau$ and $t$, and $\delta$ demonstrates sector-specific effects, and $\eta$ represents period-specific effects. This model specification helps to test whether emission growth rates converge across cross-section units by time; i.e. whether they are eager to slow down in the long-run as they approach their own long-run growth path.

In their meta-analysis of the carbon convergence literature, Acar et al. (2018) detect that the choice of different carbon convergence approaches may end up with different results. For instance, the choice of the $\beta$-convergence concept tends to increase the 
Table 1

Variables used in the analysis.

\begin{tabular}{llll}
\hline Abbr. & Definition of the variable & Unit & Data source \\
\hline $\mathrm{CO} 2$ & $\mathrm{CO}_{2}$ emissions & $\mathrm{Gg}(\mathrm{kt})$ & WIOD \\
VA & Sectoral Value-added & TLs (million) & WIOD \\
KSTOCK & Capital stock & TLs (million) & WIOD \\
EN & Emission relevant energy use & TJ & WIOD \\
\hline
\end{tabular}

likelihood of convergence, whereas the choice of the stochastic convergence concept often tends to prove carbon divergence. Besides, results may vary a lot even among the studies that focus on stochastic convergence, because utilizing different unit root tests in search for stationarity in emissions series usually implies that different assumptions prevail. A noteworthy example from Pettersson et al. (2014) is that "accounting for structural breaks and cross-sectional dependencies tends to favour the stochastic convergence hypothesis in studies based on panel data" (Acar et al., 2018).

In our investigation of $\beta$-convergence, we utilize two separate emissions indicators, one being the growth rate of sectoral emissions $\left(\mathrm{CO}_{2}\right)$ and the other being the growth of sectoral emission intensity defined as the ratio of $\mathrm{CO}_{2}$ emissions to sectoral value added (CO2/VA). The motivation behind studying the former is highly linked to the absolute emission reduction targets in regards to the global climate change concerns. Scientists have warned that life on Earth will face unforeseeable adverse consequences and be seriously threatened if the increase in surface temperature exceeds $2{ }^{\circ} \mathrm{C}$; thus, the scientific community set an ultimate target to limit the rise in global temperature by this amount $\left(2^{\circ} \mathrm{C}\right)$. Bringing this aim to the sectoral level, ideally, the total allowable $\mathrm{CO}_{2}$ emissions should be lowered significantly. Hence, sectoral "absolute" emissions need to converge to lower levels in line with the global climate change concerns. While the use of total sectoral emissions is simple and intuitive, it has some shortcomings. For instance, it does not recognize emission reduction actions implemented before 1995, which is the starting year for our sample period, and it does not easily accommodate changes in a sector's circumstances. That's why we also make use of relative emissions. The reason of the choice of sectoral value added as the denominator in the latter is that we investigate a heterogeneous sample of sectors in our analysis, and hence value added is used as a proxy for each sector's contribution to GDP.

Alongside, we focus on the coefficient $(\beta)$ of the previous emissions and emission intensities respectively in search for convergence, where the null hypothesis of divergence is $\mathrm{H}_{0}$ : $\beta=0$ for all $i$; and the alternative hypothesis of convergence is $\mathrm{H}_{\mathrm{a}}: \beta<0$ for all $i$. A negative sign for $\beta$ implies unconditional convergence in $\mathrm{CO}_{2}$ emissions. Adding control variables such as sectoral value added (VA) measured in fixed prices, real capital stock (KSTOCK) and energy use (EN) to Eq. (3) entails testing conditional convergence.

Our models are estimated via panel fixed-effects and dynamic panel (Arellano-Bond) specifications. Panel convergence has frequently been addressed by either fixed or random effects in the literature. However, it is plausible to include some dynamic effects into the standard panel model since growth of emissions accommodates dynamic effects with respect to the previous emission growth rates. In econometric theory, these dynamic effects can be integrated into the model via the inclusion of a lagged dependent variable among the regressors. While doing so, the lagged dependent variable might be correlated with the error term especially in small samples, which comes out as a problem. An instrumental variable specification is preferred to tackle this problem and, more specifically, the Generalised Method of Moments (GMM) model can be employed using the lagged values of the variables in the original model as instruments. Among several approaches to dynamic panel data models, Arellano-Bond specification is the most commonly
Table 2

Value added shares of sectors according to technology utilization.

\begin{tabular}{lll}
\hline & \multicolumn{2}{l}{ Value-added shares } \\
\cline { 2 - 3 } \cline { 2 - 3 } & 1995 & 2013 \\
\hline Primary/Low Technology Sectors & 0.18 & 0.11 \\
Medium Technology Sectors & 0.74 & 0.81 \\
High Technology Sectors & 0.08 & 0.08 \\
\hline
\end{tabular}

Source: WIOD data based on the OECD classification of technology adoption.

used one. It accounts for individual or fixed effects by differencing the data. Besides, it is the more favourable approach and results in consistent estimates when the number of cross-sections, $N$, is higher than the number of time periods, $T$ (Baltagi, 2005: 136).

The sectoral variables used in the models are described in Table 1 below:

All our data are adapted from the World Input-Output Database $(\mathrm{WIOD})^{1}$, and are further supplemented by the Turkstat data on $\mathrm{CO}_{2}$ emissions including emissions from energy, industrial processes and product use, agriculture, and waste. The names and the classification of the sectors that are under consideration are provided in Appendix A2. The summary of descriptive statistics for the variables of interest is provided in Appendix A3. We further classify our sectors in terms of their technology levels, as primary (low), medium and high technology-driven activities. This categorization is based on the OECD classification of technology adoption. WIOD data reveals that, the bulk of the manufacturing sectors display medium technology characteristics and the share of medium technology sectors account for 81\% of total value added in 2013 (see Table 2).

Fig. 4 further displays the distribution of sectoral $\mathrm{CO}_{2}$ emissions in Turkey over the sample period. In absolute emissions, Electricity, Gas and Water Supply (no. 17) and Transport (no. 21) stand out as the prominent sectors, whereas Leather and Footwear (no. 5) is the least emitting sector. The time dispersion of the emissions is the widest for Hotels and Restaurants (no. 20) as well as Wood and Products of Wood and Cork (no. 6) as illustrated in the box plot. The boxes are bounded by the first and third quartiles of the data, enclosing the middle $50 \%$ of the sample. The dots illustrate the outliers; the lines across each box show the medians; and the "+" signs indicate the "mean" observations for each sector. It is revealed that the sectors under consideration behave quite differently in their mean and median emissions during the $1995-2013$ period. When we compare sectoral emissions with respect to sectoral value added amounts, Coke, Refined Petroleum and Nuclear Fuel (no. 8) and Electricity, Gas and Water Supply (no.17) are noticeably the sectors which are performing badly. Other economy ${ }^{2}$ (no. 22) releases the lowest amount of $\mathrm{CO}_{2}$ per value added among other sectors.

\section{Empirical results on patterns of convergence of sectoral gaseous emissions}

\section{1. $\sigma$-convergence}

In order to perform a distributional analysis of emissions in the Turkish sectors, we plot the natural logarithm of the ratio of $\mathrm{CO}_{2}$ in each sector divided by average $\mathrm{CO}_{2}$ emissions in all sectors in that year, i.e. $\log$ relative emissions. To that end, Fig. 5 demon-

\footnotetext{
1 See Timmer et al. (2015) and the website http://www.wiod.org/new_site/home. htm for the details of the WIOD.

2 Other economy is comprised of the following sectors: Post and Telecommunications; Financial Intermediation; Real Estate Activities; Renting of Machinery and Equipment and Other Business Activities; Public Administration and Defence; Compulsory Social Security; Education, Health and Social Work; Other Community, Social and Personal Services; Private Households with Employed Persons.
} 


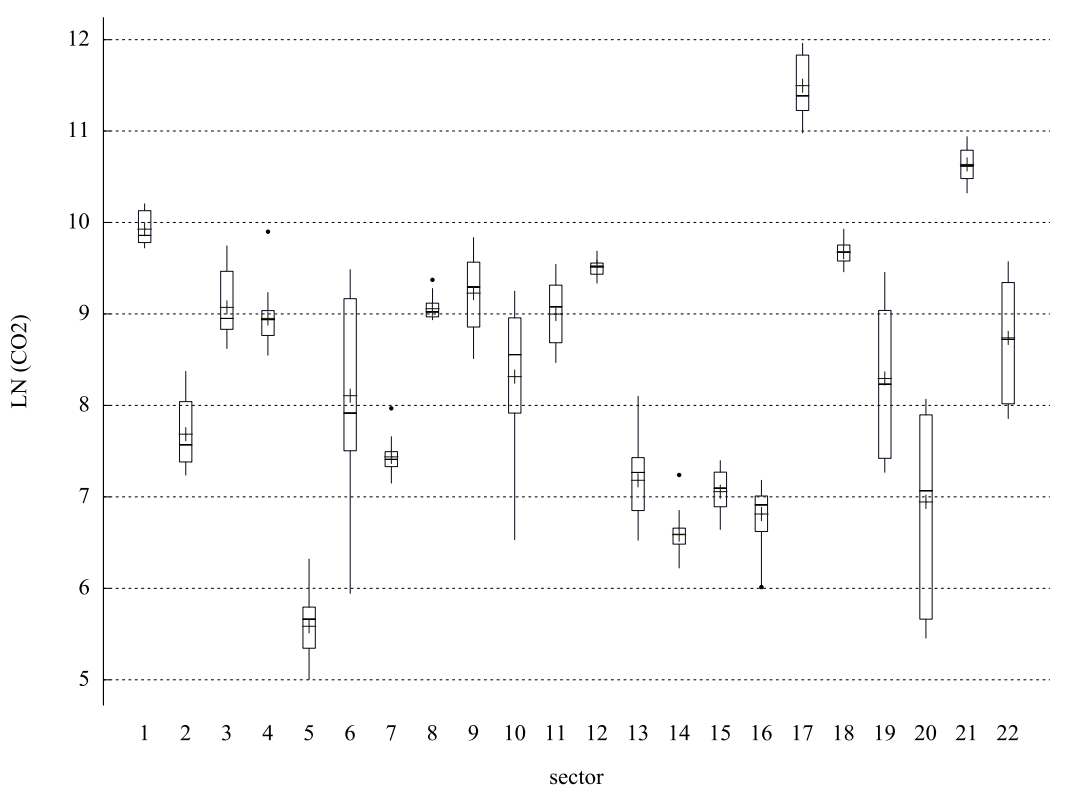

Fig. 4. Sectoral $\mathrm{CO}_{2}$ emissions distribution for 1995-2013. Note: The names of the sectors from 1 to 22 corresponding to the $\mathrm{x}$-axis are provided in Appendix A2.
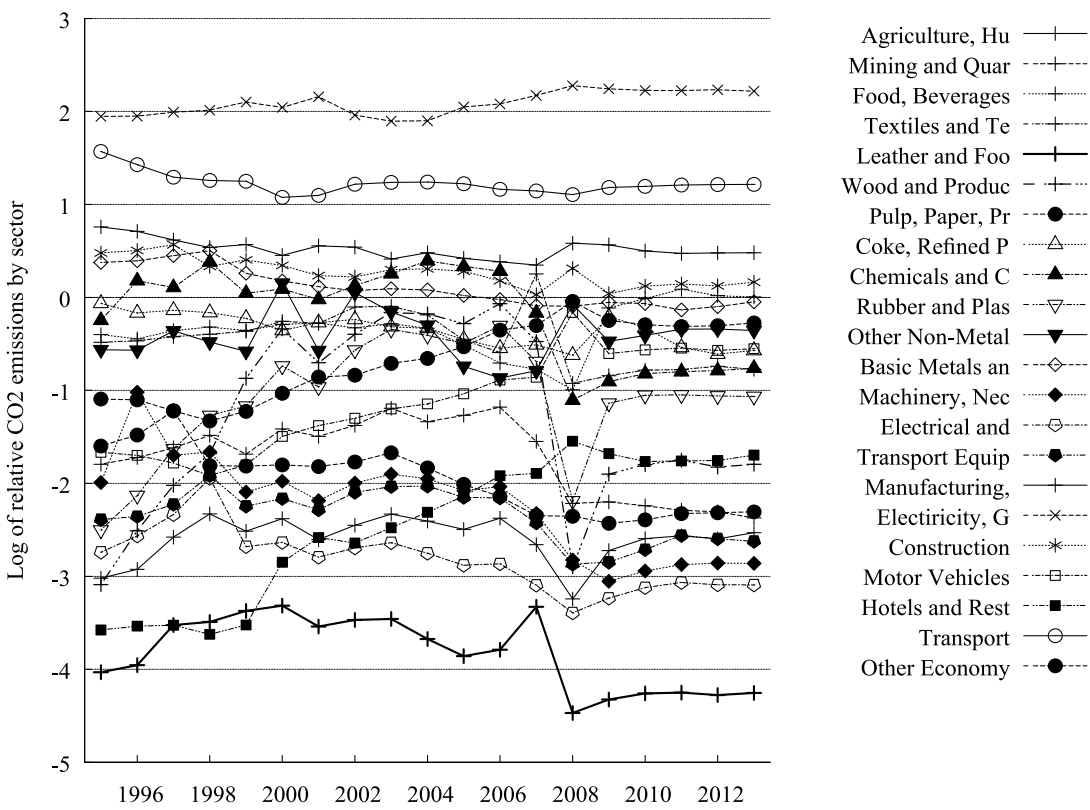

Fig. 5. Evolution of log relative $\mathrm{CO}_{2}$ emissions in each sector, 1995-2013.

strates signs of convergence to some extent, especially accelerating following the recent global crisis. It has to be noted, in this juncture, that the $2008 / 09$ crisis had a profound impact on the nature of this convergence. Fig. 6 is a direct illustrator of this phenomenon, where average log relative $\mathrm{CO}_{2}$ emissions for all sectors increase initially, make a peak in 2003 , decline substantially afterwards, and hit the bottom in 2008. There has been a recovery in mean sectoral emissions following the global turmoil.

Finally, as suggested by Barro and Sala-i-Martin (1992), Table 3 displays $\sigma$-convergence formulated by "standard deviation", which serves as a measure of cross-sectional variation of emissions over time. Apparently, the standard deviation of emissions decreased by $7 \%$ from 1995 to 2013 , documenting sigma convergence in the sectors.

\subsection{Stochastic convergence}

In order to test for stochastic convergence, we first test for crosssectional dependence for the three relevant variables derived from the sample: natural $\log$ of $\mathrm{CO}_{2}$ emissions ( $\left.\mathrm{LNCO} 2\right), \mathrm{CO}_{2}$ emissions as a share of sectoral value added (CO2/VA), and log relative $\mathrm{CO}_{2}$ emissions (LNRELCO2). The results are displayed in A4. Accordingly, we run first generation panel unit root tests for CO2/VA as we cannot reject cross-section independence, whereas we run second generation panel unit root tests for LNCO2 and LNRELCO2 as the cross-sections for these variables exhibit cross-section dependence.

Among several first generation panel unit root tests, Im et al. (2003) and Breitung (2000) tests, which are the two widely used 


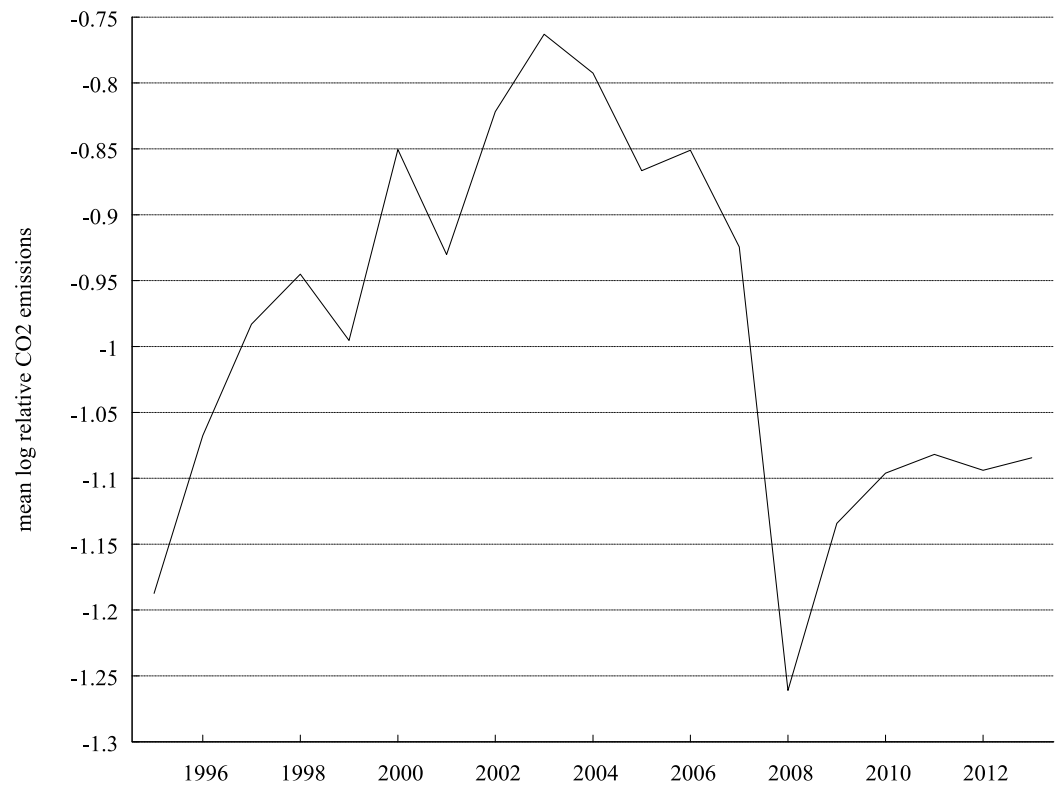

Fig. 6. Mean log relative $\mathrm{CO}_{2}$ emissions for all sectors by year.

Table 3

Standard deviation of cross-sectoral $\mathrm{CO}_{2}$ emissions from 1995 to 2013.

\begin{tabular}{|c|c|c|c|}
\hline & 1995 & 2013 & \% Change between 1995 and 2013 \\
\hline Standard deviation of cross-sectoral (log) $\mathrm{CO}_{2}$ emissions from 1995 to 2013 & 1,66 & 1,55 & $-7 \%$ \\
\hline
\end{tabular}

panel unit root tests, are employed here. The methodology is as follows. Considering an AR (1) process for panel data, $y_{i t}$ is modeled as:

$y_{i t}=\rho_{i} \mathrm{y}_{\mathrm{it}-1}+X_{i t} \delta_{\mathrm{i}}+\varepsilon_{i t}$

where $t$ and $i$ stand for time and cross-section units, respectively. Individual unit root tests such as IPS, Fisher-ADF, and Fisher-PP allow differing $\rho_{i}$ across cross-sections, whereas common unit root tests such as LLC, Breitung and Hadri assume a common unit root process, thereby taking identical $\rho_{i}=\rho$ across cross-sections, i.e. for all $i$. IPS test provides individual tests for each series. The null and alternative hypotheses of the IPS test are as follows: Ho: All panels contain unit roots. Ha: Some panels are stationary. In other words, IPS assumes that at least one of the series is stationary under the alternative hypothesis. On the other hand the corresponding hypotheses for the Breitung unit-root test are stated as follows: Ho: Panels contain unit roots. Ha: Panels are stationary. Breitung illustrates that the IPS tests suffers from a significant loss of power when individualspecific trends are included to the test and his alternative test statistic "does not employ a bias adjustment" (Baltagi, 2005: 243). As such, the Breitung test implies stronger results than the IPS. In both tests, the rejection of a unit root and the presence of stationarity imply convergence, whereas the non-rejection of a unit root implies divergence.

For LNCO2 and LNRELCO2, we employ Pesaran's CADF test (2007), which is a second generation panel unit root test. The test allows the individual autoregressive roots to differ across the cross-sectional units and is normally distributed under the null hypothesis of non-stationarity.

According to Table 4, the IPS and Breitung test results for CO2/VA suggest that unit roots cannot be rejected in the majority of the specifications, implying non-stationarity and hence, stochastic divergence. However both tests imply convergence when the series are de-trended. Pesaran's CADF test also shows that sectoral emissions and relative emissions in logarithms do not converge as the null hypothesis of unit roots cannot be rejected. To sum up, these results provide strong support for a diverging pattern in sectoral emission levels and poor evidence for convergence in emission intensity.

\section{3. $\beta$-convergence}

As described in section four, $\beta$-convergence is analyzed via panel data regression techniques here. Table 5 demonstrates the results of the analyses which are undertaken for the whole sample. Models 1_FE and $1 \_$AB represent Fixed Effects and Dynamic GMM (ArellanoBond) models respectively with the growth rate of log sectoral $\mathrm{CO}_{2}$ emissions as the dependent variable; whereas 2_FE and 2_AB represent the corresponding models with growth rate of $\mathrm{CO} 2 / \mathrm{VA}$ as the dependent variable. Accordingly, the independent variables are in natural logarithms in models 1 _FE and $1 \_\mathrm{AB}$, while they are transformed into shares in value added of each sector in models 2_FE and $2 \mathrm{AB}$.

The results imply conditional $\beta$-convergence in all cases, with the exception of 1_FE, with slight differences regarding the effects of the explanatory variables. It appears that sectoral energy use increases the emissions growth rate significantly whereas industrial value added decreases emissions growth rate contributing to convergence in model $1 \_\mathrm{AB}$. This might stem from the existence of economies of scale as the industry produces higher value added. That is to say, when the sectors have a lower output level, they would produce some amount of the "bads", i.e. emissions. As sectors grow, they do not necessarily increase their amount of $\mathrm{CO}_{2}$ proportionally to their output growth since they would require relatively less energy or other inputs per output as the production scale increases. Besides, sectoral capital stock has a slightly significant positive impact on the growth of emissions in only one of the models (1_AB).

Finally, Table 6 displays the results of the convergence analysis in three sectors classified according to their technology levels: pri- 
Table 4

Panel unit root tests.

\begin{tabular}{|c|c|c|c|c|}
\hline & & LNCO2 & $\mathrm{CO} 2 / \mathrm{VA}$ & LNRELCO2 \\
\hline \multirow[t]{4}{*}{ IPS test statistic } & With a drift and trend & & $-0.7533(0.2256)$ & \\
\hline & Without a drift, with trend & & $-2.3591(0.0092)$ & \\
\hline & With a drift, without trend & & $-1.7694(0.0384)$ & \\
\hline & Without a drift and trend & & $2.8945(0.9981)$ & \\
\hline \multirow[t]{4}{*}{ Breitung test statistic } & With a drift and trend & & $0.4861(0.6866)$ & \\
\hline & Without a drift, with trend & & $0.2554(0.6008)$ & \\
\hline & With a drift, without trend & & $-1.8267(0.0339)$ & \\
\hline & Without a drift and trend & & $1.2558(0.8954)$ & \\
\hline \multirow[t]{2}{*}{ Pesaran's CADF test statistic } & Constant & $-0.426(0.335)$ & & $-1.247(0.106)$ \\
\hline & Constant and trend & $-0.0667(0.252)$ & & $-0.942(0.173)$ \\
\hline
\end{tabular}

p-value in parentheses.

Table 5

Fixed effects and dynamic panel data estimation (Arellano-Bond) results for the whole sample.

\begin{tabular}{|c|c|c|c|c|}
\hline & $\begin{array}{l}\text { (1_FE) } \\
\text { Growth of } \mathrm{CO} 2\end{array}$ & $\begin{array}{l}\left(1 \_B\right) \\
\text { Growth of } \mathrm{CO} 2\end{array}$ & $\begin{array}{l}\left(2 \_\mathrm{FE}\right) \\
\text { Growth of } \mathrm{CO} 2 / \mathrm{VA}\end{array}$ & $\begin{array}{l}(2\lrcorner \mathrm{AB}) \\
\text { Growth of } \mathrm{CO} 2 / \mathrm{VA}\end{array}$ \\
\hline CO2_1 & $\begin{array}{l}-0.190^{* * *} \\
(-2.73)\end{array}$ & $\begin{array}{l}-0.222^{* * *} \\
(-3.98)\end{array}$ & $\begin{array}{l}-0.012^{* * *} \\
(-4.35)\end{array}$ & $\begin{array}{l}-0.006^{* *} \\
(-2.41)\end{array}$ \\
\hline VA_1 & $\begin{array}{l}-0.049 \\
(-1.08)\end{array}$ & $\begin{array}{l}-0.053^{*} \\
(-1.94)\end{array}$ & & \\
\hline KSTOCK_1 & $\begin{array}{l}0.009 \\
(0.19)\end{array}$ & $\begin{array}{l}0.053^{*} \\
(1.91)\end{array}$ & $\begin{array}{l}0.00001 \\
(0.03)\end{array}$ & $\begin{array}{l}-0.0002 \\
(-0.84)\end{array}$ \\
\hline EN_1 & $\begin{array}{l}-0.112 \\
(-1.23)\end{array}$ & $\begin{array}{l}0.197^{* * *} \\
(3.20)\end{array}$ & $\begin{array}{l}0.0009^{* * *} \\
(3.14)\end{array}$ & $\begin{array}{l}0.0006^{* *} \\
(2.40)\end{array}$ \\
\hline Constant & $\begin{array}{l}3.059^{* * *} \\
(4.89)\end{array}$ & $\begin{array}{l}-0.469 \\
(-2.03)\end{array}$ & $\begin{array}{l}0.126^{* * *} \\
(2.77)\end{array}$ & $\begin{array}{l}0.053^{* *} \\
(2.11)\end{array}$ \\
\hline Observations & 396 & 396 & 396 & 396 \\
\hline $\mathrm{F}$ & 21.26 & & 12.90 & \\
\hline $\mathrm{P}>\mathrm{F}$ & 0.000 & & 0.000 & \\
\hline r2_o & 0.017 & & 0.006 & \\
\hline chi2 & & 20.95 & & 7.19 \\
\hline $\mathrm{P}>\mathrm{chi} 2$ & & 0.000 & & 0.066 \\
\hline Sargan & & 315.24 & & 316.37 \\
\hline sarganp & & 0.847 & & 0.795 \\
\hline ar1 & & -1.97 & & -11.06 \\
\hline $\operatorname{ar} 1 p$ & & 0.049 & & 0.000 \\
\hline ar2 & & 0.68 & & 0.55 \\
\hline $\operatorname{ar} 2 p$ & & 0.495 & & 0.585 \\
\hline
\end{tabular}

$t$ statistics in parentheses. Denotations (F:F-Value, r2_o:Overall R-Square, chi2:Chi-Square, p:P-Value).

${ }^{*} p<0.1$.

** $p<0.05$.

**** $p<0.01$.

Table 6

Fixed effects estimation results for sectors classified with respect to technology.

\begin{tabular}{|c|c|c|c|c|c|c|}
\hline & $\begin{array}{l}\text { LOWTEC } \\
\text { Growth of } \\
\mathrm{CO} 2\end{array}$ & $\begin{array}{l}\text { MEDTEC } \\
\text { Growth of } \\
\mathrm{CO} 2\end{array}$ & $\begin{array}{l}\text { HITEC } \\
\text { Growth of } \\
\mathrm{CO} 2\end{array}$ & $\begin{array}{l}\text { LOWTEC } \\
\text { Growth of } \\
\text { CO2/VA }\end{array}$ & $\begin{array}{l}\text { MEDTEC } \\
\text { Growth of } \\
\text { CO2/VA }\end{array}$ & $\begin{array}{l}\text { HITEC } \\
\text { Growth of } \\
\text { CO2/VA }\end{array}$ \\
\hline $\mathrm{CO} 2 \_1$ & $\begin{array}{l}-0.426^{*} \\
(-1.71)\end{array}$ & $\begin{array}{l}-0.124 \\
(-1.54)\end{array}$ & $\begin{array}{l}-0.694^{* * *} \\
(-2.94)\end{array}$ & $\begin{array}{l}-0.050 \\
(-1.66)\end{array}$ & $\begin{array}{l}-0.009^{* *} \\
(-2.52)\end{array}$ & $\begin{array}{l}-0.021^{* *} \\
(-2.46)\end{array}$ \\
\hline VA_1 & $\begin{array}{l}-0.363 \\
(-0.90)\end{array}$ & $\begin{array}{l}-0.014 \\
(-0.18)\end{array}$ & $\begin{array}{l}-0.054 \\
(-0.87)\end{array}$ & & & \\
\hline KSTOCK_1 & $\begin{array}{l}0.287 \\
(1.30)\end{array}$ & $\begin{array}{l}-0.025 \\
(-0.38)\end{array}$ & $\begin{array}{l}-0.131 \\
(-0.92)\end{array}$ & $\begin{array}{l}0.001 \\
(0.31)\end{array}$ & $\begin{array}{l}-0.001 \\
(-1.12)\end{array}$ & $\begin{array}{l}0.006^{* *} \\
(2.55)\end{array}$ \\
\hline EN_1 & $\begin{array}{l}0.218 \\
(0.82)\end{array}$ & $\begin{array}{l}-0.183 \\
(-1.65)\end{array}$ & $\begin{array}{l}0.376 \\
(1.33)\end{array}$ & $\begin{array}{l}0.003 \\
(1.03)\end{array}$ & $\begin{array}{l}0.000 \\
(0.56)\end{array}$ & $\begin{array}{l}0.001 \\
(1.55)\end{array}$ \\
\hline Constant & $\begin{array}{l}0.499 \\
(0.33)\end{array}$ & $\begin{array}{l}3.416^{* * * *} \\
(4.20)\end{array}$ & $\begin{array}{l}3.319^{* *} \\
(2.62)\end{array}$ & $\begin{array}{l}0.189 \\
(0.54)\end{array}$ & $\begin{array}{l}0.289^{* * *} \\
(3.41)\end{array}$ & $\begin{array}{l}-0.055 \\
(-0.48)\end{array}$ \\
\hline Observations & 54 & 270 & 72 & 54 & 270 & 72 \\
\hline $\mathrm{F}$ & 1.813 & 13.199 & 8.074 & 2.236 & 11.565 & 4.584 \\
\hline $\mathrm{p}>\mathrm{F}$ & 0.117 & 0.000 & 0.000 & 0.066 & 0.000 & 0.001 \\
\hline r2_o & 0.000 & 0.013 & 0.075 & 0.098 & 0.005 & 0.015 \\
\hline
\end{tabular}

$t$ statistics in parentheses. Denotations (F:F-Value, chi2:Chi-Square, p:P-Value, r2_o:Overall R-Square).

${ }^{* *} \begin{aligned} & p<0.1 . \\ & p<0.05 . \\ & p<0.01 .\end{aligned}$ 
mary (low) technology (LOWTEC), medium technology (MEDTEC) and high technology (HITEC). As the number of observations does not satisfy model assumptions, we are not able to conduct a dynamic analysis for the specified sectors. Hence we proceed with panel fixed effects.

The results imply that the sample of medium-tech sectors does not support $\beta$-convergence in $\mathrm{CO}_{2}$ emission levels, whereas lowand high-tech sectors experience absolute convergence (although low-tech sectors do not have a highly significant coefficient for their past emissions, implying weaker convergence). The lack of support for convergence in the absolute level of emissions of medium technology sectors, which consist of the bulk of the Turkish manufacturing industries, is clearly the main driving factor in the relatively low degree of convergence at the aggregate level (observed via the corresponding beta coefficients above).

When we deal with emission intensities (CO2/VA) instead, we find that the medium-tech and high-tech sectors provide evidence for convergence while low-tech sectors do not. It can be argued that the convergence as observed within the high technology sectors can be attributed to their dynamic and open character. Openness and relative ease in access to advanced technology would have helped these sectors to internalize the external economies of scale and thereby reduce their pollution intensities. Besides, owing to high oil prices over the investigated period (especially in the 2000s), high-tech sectors, which are at the same time oil-intensive sectors such as coke, refined petroleum and nuclear fuel; chemicals and chemical products; and rubber and plastics, experienced high transformation pressures. On the other hand, capital stocks in the high-tech sectors play a positive role so as to accelerate the growth rate of $\mathrm{CO} 2 / \mathrm{VA}$.

\section{Conclusion}

In this paper we searched for the existence and nature of convergence of carbon dioxide emissions for the Turkish economy under conditions of uneven growth. We applied a series of econometric tests to deduce patterns of convergence, both at the aggregate -economy-wide level, as well as across sectors.

The simplest metric we utilized was the measure of standard deviations from the mean, i.e., the " $\sigma$-convergence". This measure was found to indicate convergence in the aggregate. A closer investigation reveals that the main driving factor behind this result had been the business cycle. In particular, the repercussions of the 2009 global crisis are observed to have a profound impact on accelerating the convergence of the $\mathrm{CO}_{2}$ emissions by way of evening out the fluctuations of the aggregate economic activity.

Second, we focused on the dynamics of stochastic convergence. This analysis was carried both on the level of $\mathrm{CO}_{2}$ emissions, and also on $\mathrm{CO}_{2}$ intensity, i.e., $\mathrm{CO}_{2}$ per value added (CO2/VA). We found that sectoral $\mathrm{CO}_{2}$ emissions per unit of value added depict stochastic convergence (when de-trended) corroborating our finding that the $\mathrm{CO}_{2}$ emissions follow the business cycle. At the aggregate level of $\mathrm{CO}_{2}$ emissions, however, patterns of convergence are dissipated and give way to a diverging trend. We then searched for evidence on $\beta$-convergence tested in conditional terms. Here we regressed the rate of growth of the level of $\mathrm{CO}_{2}$ emissions on the one period lagged value of the following explanatory variables: $\mathrm{CO}_{2}$, value added, physical capital stock, and energy utilization. In a second variant of this model, the rate of change of $\mathrm{CO} 2 / \mathrm{VA}$ intensities were regressed against the per unit value added ratios of the same variables, K/VA and EN/VA. Our results implied conditional convergence in most of the cases specified. Energy use appeared to be the most prominent indicator that drove emissions growth and emission intensity growth in the whole sample.
Finally, we distinguished the aggregate economy under a threetier sectoral specification based on their technology characteristics: low, medium, and high. We find that while the high technology sectors display strong convergence, the medium technology sectors -the bulk of Turkey's economy accounting for $80 \%$ of the aggregate value added, does not support $\beta$-convergence in $\mathrm{CO}_{2}$ emission levels. Our results further revealed that the physical capital stock fails to generate a statistically significant impact on $\mathrm{CO}_{2}$ emissions (except its positive role on the high-tech sectors' emission intensity growth). This is an unexpected result given the rather strong capital intensity of the Turkish growth path, especially over the 2000s. We interpret these observations as a result of the lack of any viable de-coupling due to the persistent structural reliance on energy resources with heavy coal and other fossil fuel intensities. Nevertheless, our results regarding physical capital are consistent with Brännlund et al. (2015), who study carbon dioxide convergence across Swedish industrial sectors and find that higher capital intensity in the selected industries gives rise to slower emissions convergence. They explain this finding by the fact that the replacement of industrial equipment, buildings, and infrastructure with low carbon ones is usually costly and time-consuming, leading to slower or no carbon convergence for the capital-intensive sectors.

To sum up, our findings do not support any conclusive evidence on the patterns of convergence. Tests of unit roots indicate that $\mathrm{CO} 2 / \mathrm{VA}$ shows divergence, with evidence of convergence only when the series are de-trended. Yet, we find diverging patterns across sectors on the basis of "aggregate" emissions. If, on the other hand, we introduce analyses of "conditional" beta-convergence, we find convergence. The diversity of these results lead us to suggest that sectoral emissions follow in general the business cycle rather than indicating de-coupling of sectoral emissions from corresponding value added increases.

Still, there are important aspects to consider that may further advance such analyses. The first important point is that carbon convergence is a historical process. In other words, carbon convergence evolves over time. This implies, in turn, that the relevant historical context of the process of sectoral carbon convergence is likely to change. However, it is difficult to determine what the relevant historical context exactly is. World energy prices are one such factor, but also global power politics and energy security issues are certainly prime candidates especially when emissions emanating from oil combustion are considered. This brings us to a second important point when carbon dioxide convergence is considered; namely that the primary energy sources that give rise to carbon emissions (oil, coal or other sources) are related to partly different technologies, and hence, sectors that utilize the afore-mentioned sources of energy as their inputs are expected to experience different transformations. For instance, high oil prices constitute a powerful transformation pressure and an incentive for technological change in the oil-consuming sectors. A response to such transformation pressures would be consistent with clear evidence for $\beta$-convergence in high-tech and medium-tech oil-consuming sectors.

Several policy implications could be derived from these results in relation to the measures applied to curb emissions in high emitting sectors. First, a sectoral focus should be the main centre of emission reduction targets if the aims of 'greening' are taken seriously. In our analyses, mostly the low and medium tech sectors prove to be experiencing non-converging patterns in emissions. High emitters like transport, electricity, gas and water supply sectors need to be the main sectors if the country intends to implement effective policies to mitigate $\mathrm{CO}_{2}$ emissions. Second, as the emission growth rates are mostly attributable to the energy intensities in the sectors, it appears necessary to reconsider the patterns of energy use taking into account the fact that fossil fuels are currently the most dominant energy sources for these sectors. Third, as tech- 
nology level makes a difference in the convergence characteristics, the country could try to transform or diversify its technological sophistication towards cleaner options. Repetto (1990: 38) suggests that "technologies that reduce environmental damages contribute to economic productivity, even though they are not costless to install or to operate". Demotivating or disincentivizing technological changes that trigger the release of harmful emissions into the environment or that facilitate the intensive use of natural resource inputs might be a desirable policy option.

Last but not the least, there is a clear need for further environmental policies and regulations to cope with future carbon dioxide emissions across the sectors. A sectoral $\mathrm{CO}_{2}$ convergence analysis of this kind might provide insights about the impacts of relevant energy and climate policies on industries with differing characteristics with respect to technology, capital composition and energy use. We propose that the efficacy of environmental (and energy) policy ultimately rests with the rate of convergence of sectoral emissions along with a warranted downward trend in emissions per unit of output.

\section{Acknowledgements}

The authors gratefully acknowledge the research support provided by TUBITAK, under grant no 114K941. A previous version of the paper was presented at the Middle East Economic Association (MEEA) meetings in conjunction with the ASSA Conference, San Francisco, in January 2016. We are grateful to Mine Çınar and the participants of the MEEA for their invaluable comments and to Yasin Kütük for his invaluable assistance with the econometric analysis. Needles to state, none of them bears any responsibility for the results and views expressed in the paper.

\section{Appendix A. Supplementary data}

Supplementary material related to this article can be found, in the online version, at doi:https://doi.org/10.1016/j.strueco.2018. 04.006.

\section{References}

Acar, S., Söderholm, P., Brännlund, R., 2018. Convergence of per capita carbon dioxide emissions: implications and meta-analysis. Clim. Policy 18 (4), 512-525 https://doi.org/10.1080/14693062.2017.1314244.

Acar, S., Yeldan, A.E., 2016. Environmental impacts of coal subsidies in Turkey: a general equilibrium analysis. Energy Policy 90, 1-15, http://dx.doi.org/10. 1016/j.enpol.2015.12.003.

Aldy, J.E., 2006. Per capita carbon dioxide emissions: convergence or divergence? Environ. Resour. Econ. 33 (4), 533-555.

Aldy, J.E., 2007. Divergence in state-level per capita carbon dioxide emissions. Land Econ. 83 (3), 353-369.

Apergis, N., Payne, J.E., 2017. Per capita carbon dioxide emissions across U.S. states by sector and fossil fuel source: evidence from club convergence tests. Energy Econ. 63, 365-372.

Arellano, M., Bond, S., 1991. Some tests of specification for panel data: Monte Carlo evidence and an application to employment equations. Rev. Econ. Stud. 58, 277-297.

Așıcl, A.A., 2015. On the sustainability of the economic growth path of Turkey: 1995-2009. Renew. Sustain. Energy Rev. 52, 1731-1741.

Baltagi, B.H., 2005. Econometric Analysis of Panel Data, 3rd edition. John Wiley\&Sons Ltd., West Sussex.

Barro, R.J., Sala-I-Martin, X., 1992. Convergence. J. Polit. Econ. 100 (2), 223-251.

Brännlund, R., Lundgren, T., Söderholm, P., 2015. Convergence of carbon dioxide performance across Swedish industrial sectors: an environmental index approach. Energy Econ. 51, 227-235.

Breitung, J., 2000. The local power of some unit root tests for panel data. In: Baltagi, B. (Ed.), Nonstationary Panels, Panel Cointegration, and Dynamic Panels, Advances in Econometrics, vol. 15. JAI, Amsterdam.

Brock, W.A., Taylor, M.S., 2010. The green solow model. J. Econ. Growth 15, $127-153$.

Bulte, E., List, J.A., Strazicich, M.C., 2007. Regulatory federalism and the distribution of air pollutant emissions. J. Reg. Sci. 47 (1), 155-178.
Camarero, M., Picazo-Tadeo, A.J., Tamarit, C., 2013. Are the determinants of $\mathrm{CO}_{2}$ emissions converging among OECD countries? Econ. Lett. 118, 159-162.

Camarero, M., Picazo-Tadeo, A.J., Tamarit, C., 2008. Is the environmental performance of industrialized countries converging? A 'SURE' approach to testing for convergence. Ecol. Econ. 66 (4), 653-661.

Carlino, G.A., Mills, L.O., 1993. Are U.S. regional incomes converging? J. Monet. Econ. 32, 335-346.

Ezcurra, R., 2007. Is there cross-country convergence in carbon dioxide emissions? Energy Policy 35 (2), 1363-1372.

Im, K.S., Pesaran, M.H., Shin, Y., 2003. Testing for unit roots in heterogeneous panels. J. Econometr. 115, 53-74.

Kumbaroğlu, G., 2011. A sectoral decomposition analysis of Turkish $\mathrm{CO}_{2}$ emissions over 1990-2007. Energy 36, 2419-2433.

Lanne, M., Linski, M., 2004. Trends and breaks in per-capita carbon dioxide emissions, 1870-2028. Energy J. 25 (4), 41-65.

Lee, C.C., Chang, C.P., 2009. Stochastic convergence of per capita carbon dioxide emissions and multiple structural breaks in OECD countries. Econ. Model. 26, $1375-1381$.

Lee, J., List, J.A., 2004. Examining trends of criteria air pollutants: are the effects of governmental intervention transitory? Environ. Resour. Econ. 29 (1), 21-37.

List, J.A., 1999. Have air pollutant emissions converged among U.S. Regions? Evidence from unit root test. South. Econ. J. 66 (1), 144-155.

McKitrick, R., Strazicich, M.C., 2005. Stationarity of global per capita carbon dioxide emissions: implications for global warming scenarios. In: Working Papers 0503. University of Guelph, Department of Economics and Finance, Ontario, Canada.

Morales-Lage, R., Bengochea-Morancho, A., Camarero, M., Martínez-Zarzoso, I., 2017. Stochastic and club convergence of sectoral CO2 emissions in the European Union. In: Universitat Jaume I Working Papers, No: 2017/1.

Morleo, G., Gilli, M., 2016. Emissioni di CO2 nei Paesi europei: un'analisi empirica sulla convergenza tra settori manifatturieri. $\mathrm{CO}_{2}$ Emissions in Europe: An Empirical Analysis on the Convergence among Manufacturing Sectors]Rivista di economia, cultura e ricerca sociale 5, 77-103.

Moutinho, V., 2015. Is there convergence and causality between the drivers of energy-related carbon dioxide emissions among the Portuguese tourism industry? Int. J. Energy Econ. Policy 5 (3), 828-840.

Moutinho, V., Robaina-Alves, M., Mota, J., 2014. Carbon dioxide emissions intensity of Portuguese industry and energy sectors: a convergence analysis and econometric approach. Renew. Sustain. Energy Rev. 40, 438-449.

Nguyen-Van, P., 2005. Distribution dynamics of $\mathrm{CO}_{2}$ emissions. Environ. Resour. Econ. 32 (4), 495-508.

Nourry, M., 2009. Re-examining the empirical evidence for stochastic convergence of two air pollutants with a pair-wise approach. Environ. Resour. Econ. 44 (4), 555-570.

Oliveira, G., Bourscheidt, D.M., 2017. Multi-sectorial convergence in greenhouse gas emissions. J. Environ. Manage. 196, 402-410.

Panopoulou, E., Pantelidis, T., 2009. Club convergence in carbon dioxide emissions. Environ. Resour. Econ. 44 (1), 47-70.

Pesaran, 2007. A simple panel unit root test in the presence of cross-section dependence. J. Appl. Econ. 22 (2), 265-312.

Pettersson, F., Maddison, D., Acar, S., Söderholm, P., 2014. Convergence of carbon dioxide emissions: a review of the literature. Int. Rev. Environ. Resour. Econ. 7 (2), 141-178.

Romero-Ávila, D., 2008. Convergence in carbon dioxide emissions among industrialised countries revisited. Energy Econ. 30 (5), 2265-2282.

Repetto, R., 1990. Environmental productivity and why it is so important. Challenge 33, 35-38.

Solow, R., 1956. A contribution to the theory of economic growth. Q. J. Econ. 70 (1) 65-94.

Strazicich, M.C., List, J.A., 2003. Are $\mathrm{CO}_{2}$ emission levels converging among industrial countries? Environ. Resour. Econ. 24 (3), 263-271.

Timmer, M.P., Dietzenbacher, E., Los, B., Stehrer, R., de Vries, G.J., 2015. An illustrated user guide to the world input-output database: the case of global automotive production. Rev. Int. Econ. 23, 575-605.

Turkish Statistical Institute (TurkStat), Available at 2015. Greenhouse Gas Emissions Inventory, 2013. http://www.turkstat.gov.tr/PreHaberBultenleri. do?id=18744.

Wang, J., Zhang, K., 2014. Convergence of carbon dioxide emissions in different sectors in China. Energy 65, 605-611.

Westerlund, J., Basher, S.A., 2008. Testing for convergence in carbon dioxide emissions using a century of panel data. Environ. Resour. Econ. 40 (1), 109-120.

World Development Indicators, 2018. Data accessed on $2^{\text {nd }}$ February, 2018. Retrieved from http://data.worldbank.org/indicator.

World Development Indicators, 2016. Data accessed on $28^{\text {th }}$ February, 2016. Retrieved from http://data.worldbank.org/indicator.

World Input-Output Database (WIOD), 2015. World Input-Output Tables. Available at http://www.wiod.org/new_site/home.htm.

Yavuz, N.C., Yilanci, V., 2013. Convergence in per capita carbon dioxide emissions among G7 countries: a TAR panel unit root approach. Environ. Resour. Econ. 54 (2), 283-291.

Yeldan, A.E., Taşçı, K., Voyvoda, E., Özsan, E., 2013. Escape from the middle income trap: which Turkey? In: Report Prepared for TURKONFED, Istanbul, March. 